\title{
Telehealth: Can Healthcare Simulation Provide Opportunities for Collaboration?
}

\section{Lee ACW ${ }^{1 *}$, Denise M. Souder ${ }^{2}$}

${ }^{1}$ Mount Saint Mary's University, Physical Therapy, 10 Chester Place, Los Angeles, California, 90007, USA

${ }^{2}$ Director of Simulation, Mount Saint Mary's University, Los Angeles, Doheny campus, 10 Chester Place, Los Angeles, CA 90007, USA

\begin{abstract}
The Health Resources Services Administration defines telehealth as the use of electronic information and telecommunication technologies to support long-distance clinical healthcare. Telehealth is becoming one of the disruptive technologies that will transform healthcare in the 21 st century. Clinical implementation of telehealth has occurred in nursing and physical therapy. Concurrently, use of health care simulations in academia has occurred recently. The aim of this short communication is provide clinical perspectives from physical therapy and nursing in order to advance telehealth collaborations. One opportunity in academia is to further investigate telehealth healthcare simulation as an interprofessional collaboration between curricula. Future studies must address access, cost, and chronic disease management in telehealth collaborations.
\end{abstract}

Keywords: Telehealth; Healthcare simulation; Nursing; Physical therapy

\section{Introduction}

The concept of telehealth in United States was first introduced in 1924 issue of Radio News [1]. This newspaper edition featured a drawing of a physician auscultating his patient through a radio with a stethoscope. In reality, a clinical case report in the Lancet described a physician interacting with a caretaker and a child via telephone to diagnose a child's cough in late 1890 [2]. In late 1950's, telemedicine implementation programs were established in tele-radiology by Albert Jutras in Canada, and the Nebraska Psychiatric Institute initiated a telepsychiatry program in conjunction with the University of Nebraska. By the 1960's, the National Aeronautics and Space Administration (NASA) established a telemedicine program to monitor its astronauts, as well as assisted in international emergency earthquake disaster relief telemedicine efforts. In 1980's, the first telemedicine remote kiosk program was established in Boston international airport to triage airport travelers encountering medical emergencies. In 1993, The American Telemedicine Association (ATA) was established as a nonprofit organization to promote access to medical care for consumers and health professionals via telecommunications technology. Telehealth nursing and telerehabilitation special interest groups exist within ATA [3,4]. Currently, the Center for Medicare and Medicaid (CMS) has established a fiscal budget for telemedicine for eligible telehealth providers for reimbursement in Medicare and Medicaid programs $[5,6]$. With advancing technologies in practice, telehealth has an opportunity to provide timely access and connected care for patients and practitioners in the future.

\section{Telehealth nursing}

The first published telenursing evidence was conducted by Mary Quinn, RN in 1974, where she described working in a Boston Hospital Telemedicine Center and triaging patients remotely who were at Logan Airport [7]. Today, telehealth nursing is practiced in areas where access and clinical efficiency can be facilitated remotely in teleICU, teletriage, teletrauma, telestroke, telepediatrics, telemental health, telecardiology, telehomecare, and forensic telenursing. For example, home telehealth nurses use systems that allow monitoring of patient data and physiologic parameters and biomarkers via telehealth [8]. For nursing, a key set of competencies have been developed by the American Academy of
Ambulatory Care Nurses (AAACN) [9] and the American Nurses Association (ANA) [10]. International telenursing competencies are available from the International Council of Nursing (ICN) [11] as well. Nursing profession has led in areas of interstate licensure compacts for telehealth practice as a model regulatory body for protecting the rights and safety of consumers and practitioners.

\section{Telehealth in physical therapy}

In physical therapy literature, telehealth was first cited by American Physical Therapy Association (APTA) President, Jan Richardson, in her Presidential address in 2000. In her address, "virtual care" was seen as an opportunity for physical therapy profession in the future [12]. The APTA defines telehealth as the use of secure electronic communications to provide and deliver a host of health-related information and health care services; including, but not limited to physical therapy-related information and services for patients and clients [13]. Strong evidence is noted in telehealth outpatient and in-home total knee arthroplasty rehabilitation with non-inferior clinical outcomes [14,15]. Other areas of practice in telestroke [16], cardiac rehabilitation [17] and skilled nursing facilities supervision between physical therapists and support personnel [18] are emerging. A Blueprint for Telerehabilitation [19] was developed by the Telerehabilitation special interest group of ATA to support telehealth while the Federation of State Boards of Physical Therapy (FSBPT) developed administrative, clinical, technical, and ethical guidelines to support model recommendations for physical therapy licensure board members in 2015 [20]. Physical therapy profession has led in areas of musculoskeletal telehealth evidence to advance research that can translate to practice for consumers and practitioners.

*Corresponding author: Lee ACW, Associate Professor, Mount Saint Mary's University, Physical Therapy, 10 Chester Place, Los Angeles, California 90007 USA, Tel: 2134772981; Fax: 213-477-2600; E-mail: allee@msmu.edu

Received April 11, 2016; Accepted May 24, 2016; Published May 31, 2016

Citation: Lee ACW, Souder DM (2016) Telehealth: Can Healthcare Simulation Provide Opportunities for Collaboration? Adv Practice Nurs 2:112. doi:10.4172/2573-0347.1000112

Copyright: $\odot 2016$ Lee ACW, et al. This is an open-access article distributed under the terms of the Creative Commons Attribution License, which permits unrestricted use, distribution, and reproduction in any medium, provided the original author and source are credited. 


\section{Healthcare simulation}

As with telehealth, the use of simulation across the health professions has increased over recent years. Initiatives for increased patient safety, shorter hospital stays, competition for clinical sites, disparities across clinical sites, limited student access to patient records, and faculty shortages in the clinical settings have been strong driving forces in the move towards the use of simulation [21]. Clinical experiences can be simulated through different methods, offering learners and practitioners a safe environment to practice their skills in the cognitive, psychomotor, and affective domains without harm to patients. Simulation includes case studies, partial task trainers, virtual patients, low fidelity human patient simulators, high fidelity human patient simulators, standardized patients, hybrids, and virtual patients [22]. Since simulated experiences stimulate critical thinking, decisionmaking and involve clinical judgment, simulation has become an integral part of team training and education in the health professions [23]. By providing the adult learners and practitioners with actual experiential learning, simulation-based education will continue to be a valuable teaching modality as technology advances are incorporated into the daily practices of health professionals. Although healthcare simulation evidence is rich in nursing, it is still evolving in physical therapy literature [24]. Therefore, healthcare simulation is an emerging area in healthcare where telehealth opportunities exist to use standardized patients in teaching remote clinical encounters in academic and clinical environments [25]. We, at the Experiential Learning Center at Mount Saint Mary's University, Los Angeles, are forging collaborations and evaluating outcomes with healthcare simulation between nursing and physical therapy curricula.

\section{Directions for further studies}

The Institute of Medicine reported interprofessional education (IPE) and collaboration within health disciplines are key necessity for improving health care in the 21 st century [26]. The interprofessional learning continuum includes outcomes that address the learner and health systems that actively seek to identify major enabling and interfering factors. Telehealth is one enabling factor that can promote IPE in nursing and physical therapy professions. Concurrently, health care simulations have provided opportunities for health professions to advance learning and clinical practice with technology in academic and clinical environments. However, evidence for academic and clinical training in telehealth and healthcare simulations with telehealth are lacking. Furthermore, telehealth evidence has not been supportive of hospital admissions for certain chronic disease monitoring at home [27]. In a researcher blind, multicenter trial of telemonitoirng of 128 adults with at least one admission for chronic obstructive pulmonary disease (COPD) compared to usual care, the mean number of COPD admissions were similar in both groups over one year. In addition, a quality assessment of systematic reviews on telerehabilitation studies found that there is insufficient evidence to confirm that telerehabilitation is a cost-saving or cost-effective solution as well as lacking support for stroke management [28]. One opportunity for further study exists for IPE by connecting remote patients rural communities [28] to health professionals who can coordinate care in our current health systems. For example, the comprehensive care for joint replacement (CJR) model is testing bundled payment and quality measurement for an episode of care associated with hip and knee replacements to encourage hospitals and post-acute providers to work together to improve the quality and coordination of care from the initial hospitalization through recovery [29]. This CJR model will impact both nursing and physical therapy professions since cost effective management of patients with total hip or knee replacements are essential in order to deliver high quality outcomes with limited resources in various communities. Hence, empirical evidence is needed for using telehealth as well as healthcare simulations to address the CJR model. As mentioned earlier, clinical outcomes with telehealth physical therapy was demonstrated to be non-inferior to usual care for patients with total knee replacements in outpatient, in-home, and asynchronous environments [30]. However these telehealth findings only addressed cost of delivery of care in Canada. Therefore, future investigation to address cost in CJR with telehealth as well as managing chronic disease at the right place for right patients are necessary. We believe both nursing and physical therapy telehealth and health care simulation collaborations may serve to address education, practice, and research in the future.

In conclusion, disruptive innovations in healthcare including telehealth and healthcare simulation provide opportunities for adult learners and practitioners to collaborate in order to deliver high quality outcomes. But, these novel opportunities must serve to deliver real performance in practice that drive health reform for improving patient outcomes which requires further investigation.

\section{References}

1. (2012) American Telemedicine Association (ATA). What is telemedicine

2. Bashshur RL, Shannon GW (2009) History of Telemedicine: Evolution, context and transformation. Mary Ann Liebert, Inc.

3. (2012) American Telemedicine Association (ATA). Telehealth Nursing Special Interest Group.

4. (2012) American Telemedicine Association (ATA). Telerehabilitation Specia Interest Group.

5. (2016) Centers for Medicare \& Medicaid Services (CMS). Telehealth.

6. (2012) American Telemedicine Association (ATA). State Telemedicine Gaps Analysis.

7. (2012) American Telemedicine Association (ATA). Telehealth nursing fact sheet

8. Greenwood DA, Young HM, Quinn CC (2014) Telehealth remote monitoring systematic review: Structured self-monitoring of blood glucose and impact on A1C. J Diabetes Sci Technol 8: 378-389.

9. (2016) American Academy of Ambulatory Care Nursing (AAACN). Telehealth Nursing Practice.

10. (1999) American Nurses Association (ANA) Competencies for telehealth technology in nursing.

11. International Council of Nurses (ICN) (2015) Professional Resources.

12. Richardson JK (2000) Tipping the scales of time. Phys Ther 80: 1121-1124.

13. (2015) American Physical Therapy Association (APTA). Telehealth.

14. Russell TG, Buttrum P, Wootton, R, Jull GA (2011) Internet-based outpatient telerehabilitation for patients following total knee arthroplasty: a randomized controlled trial. J Bone Joint Surg Am 93: 113-120.

15. Tousignant M, Moffet $H$, Boissy $P$, Corriveau H, Cabana $F$, et al. (2011) A randomized controlled trial of home teleerehabilitation for post-knee arthroplasty. J Telemed Telecare 17: 195-198.

16. Chumbler NR, Quigley P, Li X, Morey M, Rose D, et al. (2012) Effects of telerehabilitation on physical function and disability for stroke patients: a randomized, controlled trial. Stroke. 43: 2168-2174.

17. Scalvini S, Zanelli E, Comini L, Dalla Tomba M, Troise G, et al. (2013) Home-based versus in-hospital cardiac rehabilitation after cardiac surgery: a nonrandomized controlled study. Phys Ther 93: 1073-1083.

18. Lee AC, Billings M (2016) Telehealth implementation in a skilled nursing facility case report for physical therapist practice in washington. Phys Ther 96: 252259.

19. Brennan DM, Tindall L, Theodoros D, Brown J, Campbell M, et al. (2011) A blueprint for telerehabilitation guidelines. Telemed J E Health 8: 662-665. 
Citation: Lee ACW, Souder DM (2016) Telehealth: Can Healthcare Simulation Provide Opportunities for Collaboration? Adv Practice Nurs 2:112. doi:10.4172/2573-0347.1000112

Page 3 of 2

20. (2016) Federation of State Boards of Physical Therapy (FSBPT) Telehealth in physical therapy policy recommendations for appropriate regulation.

21. Hayden JK, Smiley RA, Alexander M, Kardong-Edgren S, Jeffries PR (2014) The NCSBN National Simulation Study: A Longitudinal, Randomized, Controlled Study Replacing Clinical Hours with Simulation in Prelicensure Nursing Education. Journal of Nursing Regulation 5: C1-S64.

22. Cannon-Diehl MR (2009) Simulation in Healthcare and Nursing: State of the Science. Crit Care Nurs Q 32: 128-136.

23. Yudkowsky R, Valdes W, Raja S, Kiser R (2011) Assessing residents' telehealth communication skills using standardized patients. Med Educ 45: 1155.

24. Bednarek M, Downey P, Williamson A, Ennulat C (2014) The use of human simulation to teach acute care skills in a cardiopulmonary course: A case report. J Phys Ther Edu 28: 27-34.

25. Konia M, Yao A (2013) Simulation - a new educational paradigm? J Biomed Res 27: 75-80.
26. (2015) Institue of Medicine (IOM) Measuring the impact of interprofessional education on collaborative practice and patient outcomes. The National Academies of Sciences.

27. Pinnock H, Hanley J, McCloughan L, Todd A, Krishan A, et al. (2013) Effectiveness of telemonitoring integrated into existing clinical services on hospital admission for exacerbation of chronic obstructive pulmonary disease: researcher blind, multicentre, randomised controlled trial. BMJ 347: f6070

28. Rogante M, Kairy D, Giacomozzi C, Grigioni M (2015) A quality assessment of systematic reviews on telerehabilitation: what does the evidence tell us? Ann $1^{\text {st }}$ Super Sanita 51: 11-18.

29. (2016) Centers for Medicare \& Medicaid Services (CMS) Comprehensive Care for Joint Replacement Model.

30. Bini SA, Mahajan J (2016) Clinical outcomes of remote asynchronous telerehabilitation are equivalent to traditional therapy following total knee arthroplasty: A randomized control study. J Telemed Telecare 1-9. 